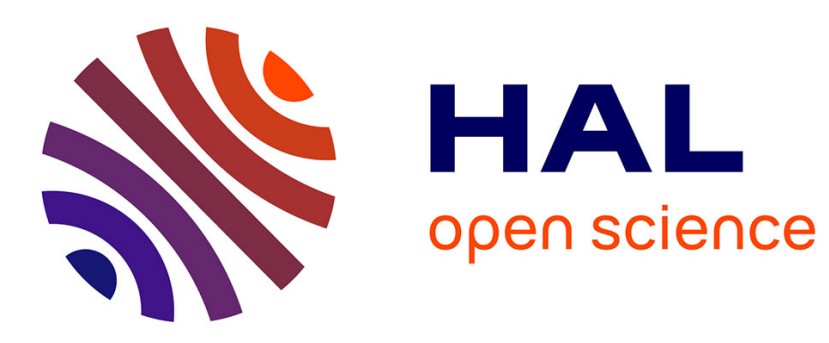

\title{
A fluid smectic A antiphase in a pure nitro rod-like compound
}

\author{
F. Hardouin, G. Sigaud, Nguyen Huu Tinh, M.F. Achard
}

\section{To cite this version:}

F. Hardouin, G. Sigaud, Nguyen Huu Tinh, M.F. Achard. A fluid smectic A antiphase in a pure nitro rod-like compound. Journal de Physique Lettres, 1981, 42 (3), pp.63-66. 10.1051/jphyslet:0198100420306300 . jpa-00231874

\section{HAL Id: jpa-00231874 https://hal.science/jpa-00231874}

Submitted on 1 Jan 1981

HAL is a multi-disciplinary open access archive for the deposit and dissemination of scientific research documents, whether they are published or not. The documents may come from teaching and research institutions in France or abroad, or from public or private research centers.
L'archive ouverte pluridisciplinaire HAL, est destinée au dépôt et à la diffusion de documents scientifiques de niveau recherche, publiés ou non, émanant des établissements d'enseignement et de recherche français ou étrangers, des laboratoires publics ou privés. 


\title{
A fluid smectic A antiphase in a pure nitro rod-like compound
}

\author{
F. Hardouin, G. Sigaud, Nguyen Huu Tinh and M. F. Achard \\ Centre de Recherche Paul-Pascal, C.N.R.S., Université Bordeaux I, 33405 Talence Cedex, France
}

(Reçu le 31 octobre 1980, accepté le 16 décembre 1980)

\begin{abstract}
Résumé. - Une transition entre une phase smectique $A$ et une antiphase smectique $A\left(S_{\tilde{\mathbf{A}}}\right)$ est découverte pour la première fois dans un composé pur : le nitrobenzoyloxybenzoate d'heptylphényl.

Jusqu'à présent les anomalies de périodicité liées à l'existence de telles transitions ne s'observaient que dans des systèmes cyanés. De plus, la phase solide de l'homologue inférieur de cette série nitrée est étrangement influencée par ces mêmes anomalies de périodicité.
\end{abstract}

\begin{abstract}
A transition between a smectic A phase and a smectic A antiphase ( $\left.\mathbf{S}_{\tilde{\mathbf{A}}}\right)$ is observed for the first time in a pure compound : the nitrobenzoyloxybenzoate of heptylphenyl.

So far, the anomalies of periodicities which are connected to this type of transition were only detected in cyano systems. Moreover, the solid phase of the inferior homologue of this nitro series is surprisingly influenced by similar anomalies of periodicities.
\end{abstract}

1. Introduction. - Our earlier works about long aromatic cyano-derivatives gave evidence for several new transitions between disordered mesophases (nematic and smectic A) [1-3]. In particular the series of cyanobenzoyloxybenzoates of alkylphenyl $\left(\mathrm{DB}_{n} \mathrm{CN}\right.$ for short, $n$ being the number of carbon of the alkyl chain) has provided some unexpected phenomena connected to anomalies of periodicities.

Let us recall briefly some peculiar recent results published elsewhere $[4,5]$ which can help the understanding of next section :

(i) $A S_{A_{A}}-S_{A_{2}}$ transition is evidenced in the pure $\mathrm{DB}_{7} \mathrm{CN}$ [4].

In the high temperature $S_{A}$ phase two collinear wavelengths coexist such that $q_{2} \neq 2 q_{1}\left(q_{2} / q_{1} \simeq 1.8\right)$. The layer spacing

$$
d=\frac{2 \pi}{q_{1}} \simeq 1.6 l
$$

( $l$ being the molecular length). The other wavelength corresponds to a highly damped modulation. At the transition we observe the commensurate locking of these two wavelengths with $q_{2}=2 q_{1}$ keeping only one modulation such that $d \simeq 2 l$, characteristic of what we named a bimolecular smectic $\mathrm{A}\left(\mathrm{S}_{\mathrm{A}_{2}}\right)$ (previously revealed in pure $\mathrm{DB}_{5} \mathrm{CN}$ and $\mathrm{DB}_{6} \mathrm{CN}$ ).

(ii) There exists a smectic $A$ antiphase $\left(\mathrm{S}_{\tilde{\mathrm{A}}}\right)$ obtained from a binary mixture of $\mathrm{DB}_{6} \mathrm{CN}$ (or $\mathrm{DB}_{5} \mathrm{CN}$ ) with another cyano compound [5] : this phase is intermediate between a monomolecular $\mathrm{S}_{\mathrm{A}_{1}}$ phase and a bimolecular $\mathrm{S}_{\mathrm{A}_{2}}$ phase. In the high temperature $S_{A_{1}}$ phase, two wavelengths coexist such that $q_{2} / q_{1} \simeq 1.8$ but, in this case, with $d=2 \pi / q_{2} \simeq l$ and with $q_{1}$ characteristic of a damped modulation.

Then, with decreasing temperature, $q_{1}$ loses its unidimensional form. At the change into $S_{\tilde{\mathrm{A}}}$ antiphase, long range lateral fluctuations take place in the layers and $q_{1}$ and $q_{2}$ seem now commensurate along the $z$ axis $(\langle 00 l\rangle$ row, normal to the layers) : $q_{2} / q_{1 z}=2$.

At last, this lateral modulation mode collapses and gives rise to the $\mathrm{S}_{\mathrm{A}_{2}}$ phase : $q_{2} / q_{1}=2$.

Thus, the main cause of such behaviours $\left({ }^{1}\right)$ appears to be the coexistence along $z$ of two periodicities either commensurate or incommensurate $[6,7]$ : one corresponds to the molecular length (experimentally characterized by $q_{2}$ which is constant for a given system) and the other comes from the arrangement of the dipoles. Therefore, we have not varied the values of these parameters but only replaced the cyano head by a more hindering one.

2. Experimental. - We report some new observations obtained from nitro-compounds directly derived from the cyanodibenzoate series. Thus, the formula

(1) Presented at the 8th International Liquid Crystal Conference, Kyoto, June 1980. 
of the substances, synthetized in our laboratory, is the following :

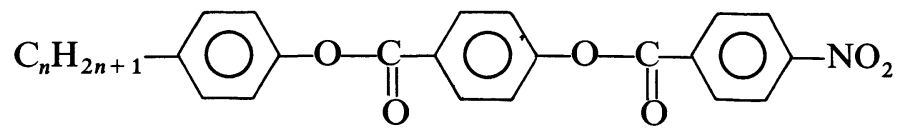

$\mathrm{DB}_{n} \mathrm{NO}_{2}$ for short by similarity with the indexing of the cyano-derivatives. We note that the value of the nitro dipole is quasi-similar to the cyano one : $\sim 4 \mathrm{D}$. The D.S.C. investigations of the $\mathrm{DB}_{7} \mathrm{NO}_{2}$ show three mesomorphic states (Fig. 1) whereas the classical

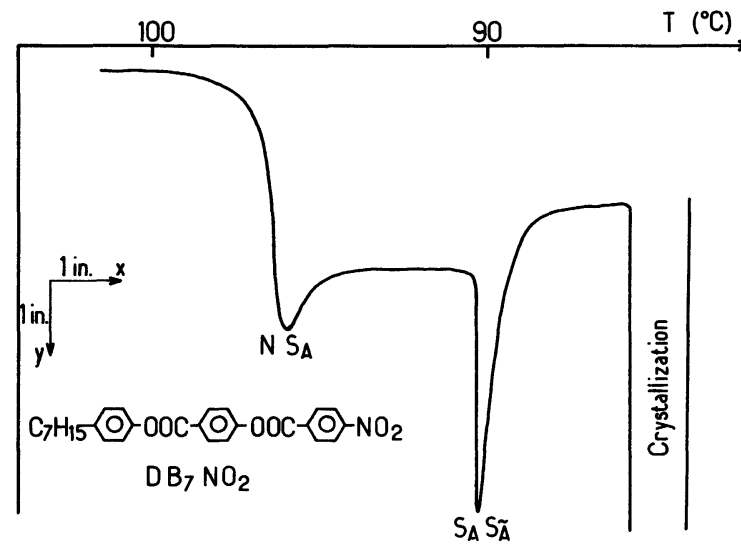

Fig. 1. - D.S.C. recording of pure $\mathrm{DB}_{7} \mathrm{NO}_{2}$ (decreasing temperature).

a)

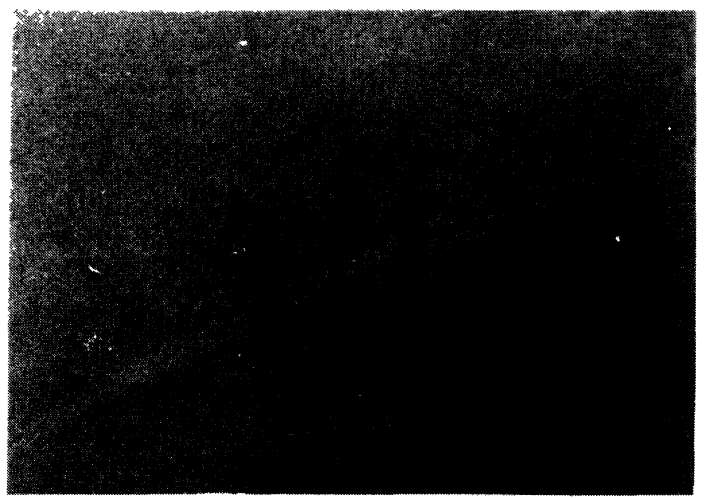

b)

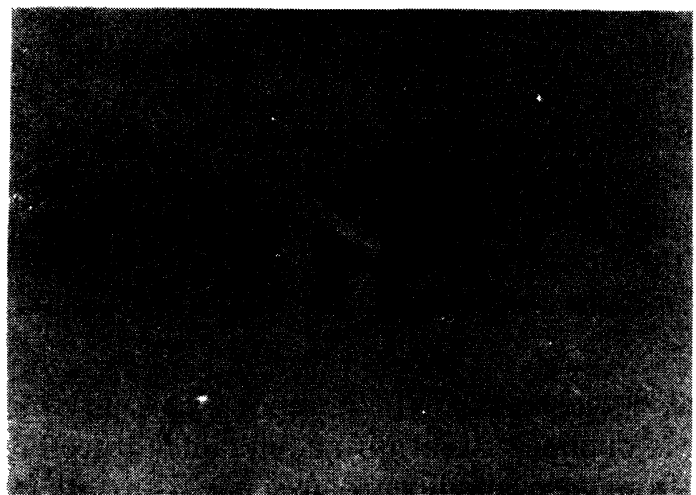

Fig. 2. - a) X-ray pattern of the high temperature phase of $\mathrm{DB}_{7} \mathrm{NO}_{2}$. Orientated sample : the magnetic field direction is parallel to the $\langle 00 l\rangle$ row $\left(z\right.$ axis). b) X-ray pattern of the $S_{\tilde{A}}$ antiphase of $\mathrm{DB}_{7} \mathrm{NO}_{2}$. microscopic observations between glass slide and cover slip reveal only two mesophases : a nematic and only one smectic A phase. This apparent discrepancy already discussed in our previous papers $[3$, 5] is solved by the way of X-ray technique as demonstrated by the bright patterns of figure 2 : the first one, taken at $94{ }^{\circ} \mathrm{C}$ presents (i) one Bragg spot corresponding to a mass density periodicity characterized by a wavelength $d \simeq$ one molecular length $l$ and (ii) a strong diffuse scattering corresponding to fluctuations the periodicity of which along the $\langle 00 l\rangle$ row ( $z$ axis) appears incommensurate with $d\left(q_{1} / q_{2} \neq 2\right)$. Moreover one can remark the tendency for this diffuse spot to split off the $z$ axis. This phase is a $\mathrm{S}_{\mathrm{A}}$ phase with $d \simeq l$ and anomalies of periodicities similar to those described elsewhere $[3,5]$. Then at $T=87^{\circ} \mathrm{C}$ (below the second enthalpic peak) the $\mathrm{X}$-ray pattern is modified in that manner : the diffuse scattering seems now condensed in the form of two acute Bragg spots located out the $z$ axis (clearly visible on the left part of the plate $b$ ) $\left({ }^{2}\right)$. In addition these spots have moved such that $q_{1 z}$ seems now commensurate with $q_{2}$ (which is for its part not modified) : $q_{1 z} / q_{2}=2$. This pattern is characteristic of the fluid $\mathrm{S}_{\widetilde{\mathrm{A}}}$ antiphase that we have previously discovered in a cyano binary mixture [5]. This result is confirmed by the microscopic observation of the free surface of a droplet which shows a texture change at the temperature of transition determined by D.S.C. $\left(90^{\circ} \mathrm{C}\right)$. Note that this textural change is different from the one observed in the first example of $S_{\widetilde{A}}$ antiphase [5].

Thus, these experiments give evidence for the first $S_{\mathrm{A}}$ to $S_{\tilde{\mathrm{A}}}$. transition in a pure compound, namely the nitrobenzoyloxybenzoate of heptylphenyl $\left(\mathrm{DB}_{7} \mathrm{NO}_{2}\right)$.

Now, the homologue with $n=6\left(\mathrm{DB}_{6} \mathrm{NO}_{2}\right)$ exhibits only one smectic phase characterized by optical microscopy as well as by D.S.C. measurements $\left(T_{\mathrm{N}-\mathrm{S}}=91^{\circ} \mathrm{C}\right)$. The X-ray pattern indicates undoubtedly that it is a smectic A phase like the high temperature $S_{A}$ phase of the $\mathrm{DB}_{7} \mathrm{NO}_{2}$.

It is obvious that this phase differs from a $\mathrm{S}_{\mathrm{A}_{2}}$ phase on the binary phase diagram of figure 3 , in which $\mathrm{DB}_{6} \mathrm{NO}_{2}$ and $\mathrm{DB}_{6} \mathrm{CN}$ are mixed. In fact three smectic $A$ domains appear : the $S_{A_{2}}$ phase on the $\mathrm{DB}_{6} \mathrm{CN}$ side, the $\mathrm{S}_{\mathrm{A}}$ phase of the pure $\mathrm{DB}_{6} \mathrm{NO}_{2}$ and, as could be expected from the polymorphism of the $\mathrm{DB}_{7} \mathrm{NO}_{2}$, a $\mathrm{S}_{\tilde{\mathrm{A}}}$ domain comprised between the $S_{A}$ and the $S_{A_{2}}$ phases. But in the case of the pure $\mathrm{DB}_{6} \mathrm{NO}_{2}$ the $\mathrm{S}_{\tilde{\mathrm{A}}}$ phase is virtual since crystallization occurs first.

Nevertheless a striking fact must be pointed out from the diagram of figure 3 and the D.S.C. recording of pure $\mathrm{DB}_{6} \mathrm{NO}_{2}$ represented on figure 4 .

$\left({ }^{2}\right)$ We point out that the Bragg reflection corresponding to the monomolecular modulation is not split out the $z$ axis in the figure $2 b$. Thus, this spot is not the second order of reflection of a smectic $\mathrm{C}$ tilted structure. 


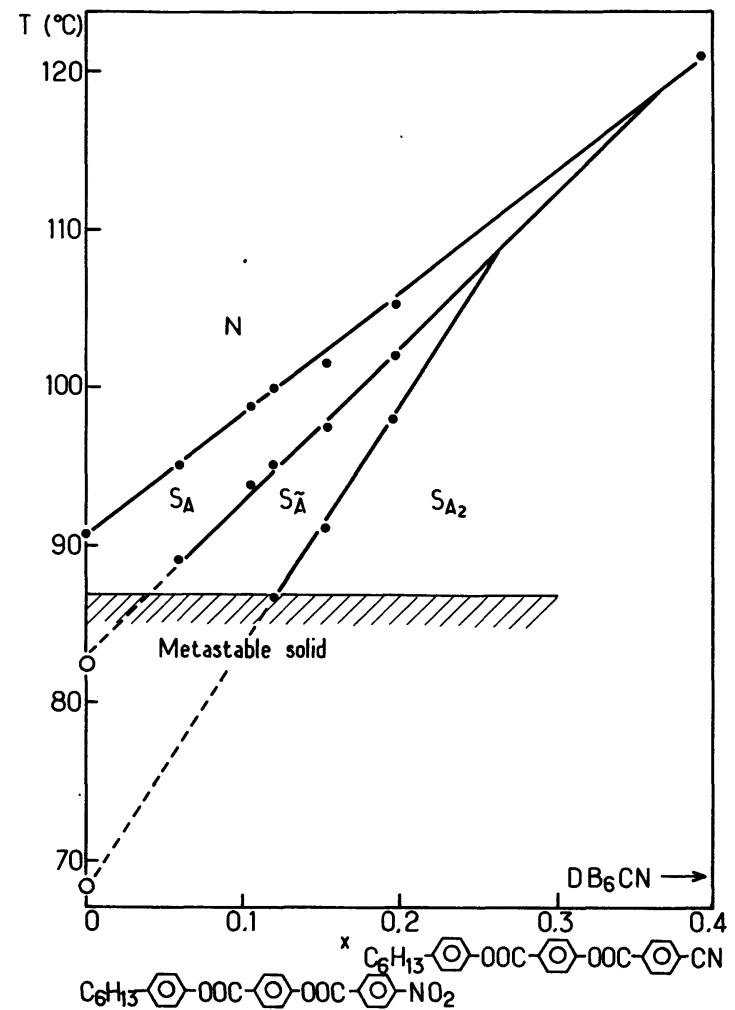

Fig. 3. - Binary isobaric diagram between $\mathrm{DB}_{6} \mathrm{NO}_{2}$ (left side) and $\mathrm{DB}_{6} \mathrm{CN}$ (right side). The horizontal line represent the transition to a metastable crystalline form. (Diagram obtained from D.S.C. measurements.)

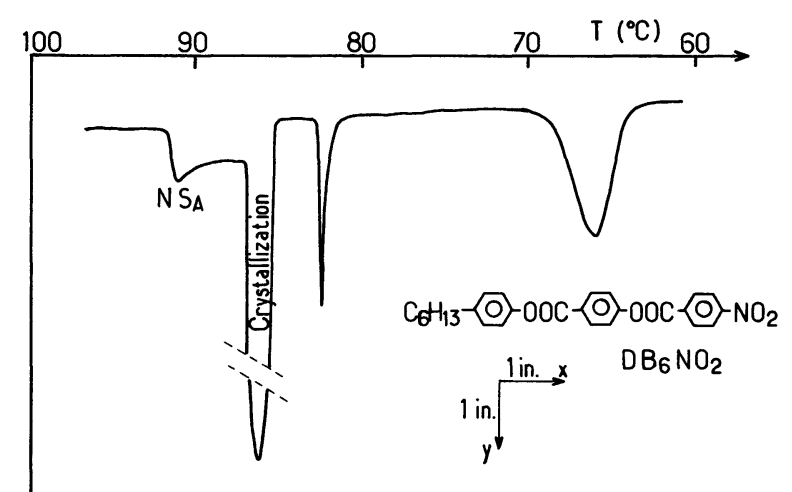

Fig. 4. - D.S.C. recording of pure $\mathrm{DB}_{6} \mathrm{NO}_{2}$ (decreasing temperature).

Indeed, one can remark on this enthalpic spectrum that the crystallization to a metastable solid occurs a few degrees lower than the $\mathrm{N}-\mathrm{S}_{\mathrm{A}}$ transition : it corresponds to the large peak at $86^{\circ} \mathrm{C}$. But with decreasing temperature two additional small peaks appear successively. Their shape is qualitatively the same as those corresponding respectively to $S_{A^{-}}-S_{\tilde{A}}$ and $S_{\tilde{A}}-S_{A_{2}}$ transitions. Now if we put the transition temperatures assigned to these peaks on the diagram of figure 3 (white circles) it is very surprising to find that these points correspond to the extrapolations of the $S_{A}-S_{\widetilde{A}}$ and $\mathrm{S}_{\tilde{\mathrm{A}}^{-}}-\mathrm{S}_{\mathrm{A}_{2}}$ lines (dotted lines). Consequently we can propose that the kind of transitions we have observed in the fluid $S_{A}$ phases occurs as well in a solid matrix (we notice that this happens only in the case of a metastable crystalline form and that the two additional peaks do not appear when the stable solid is established).

More X-ray experiments are required but the metastability of the crystalline form makes them difficult.

May be the metastable solid exists in an incommensurate state in the temperature range defined by these two small peaks (like the one observed by Brownsey and Leadbetter [8] in $S_{E}$ phase). This state, in terms of anomalies of periodicity, would be intermediate between a first commensurate one with one molecular length periodicity along $z$ and a last one with a commensurate locking and a doubling of the periodicity along $z$. Up to now this assumed commensurateincommensurate-commensurate sequence is not observed in smectic A matrices because the fluidity of this medium allows sort of an antiphase structure $S_{\widetilde{A}}$ (commensurate along $z$ ) while such a compromise would be prevented in a rigid solid matrix. However, the theoretical diagram of reference [9] predicts the possible existence of commensurate and incommensurate states as well as of an antiphase in smectic A systems of polar molecules. The stability of these phases depends not only on temperature, but also on the value of elasticity parameters which, of course, differ greatly in the case of solids.

3. Conclusion. - As the $\mathrm{DB}_{n} \mathrm{CN}$ compounds, the nitro derivatives $\left(\mathrm{DB}_{n} \mathrm{NO}_{2}\right)$ provide smectic $A$ phases with anomalies of periodicities. Nevertheless, as so far as we have investigated this series, we do not find a $\mathrm{S}_{\mathrm{A}_{2}}$ phase contrary to the $\mathrm{DB}_{n} \mathrm{CN}(n=5,6,7)$. On the other hand, the $\mathrm{DB}_{7} \mathrm{NO}_{2}$ is the first example of a pure compound exhibiting a $\mathrm{S}_{\mathrm{A}}-\mathrm{S}_{\tilde{\mathrm{A}}}$ antiphase transition. This last phase seems stabilized by the higher hindrance of the $\mathrm{NO}_{2}$ group. Since our studies of binary mixtures have shown that the $S_{\tilde{\mathrm{A}}}$ antiphase can be considered as a precursor of the $\mathrm{S}_{\mathrm{A}_{2}}$ phase, may be we can expect the occurrence of this bimolecular smectic $A_{2}$ for the higher homologues of the series. In addition, the extrapolation of these unusual modulations in a solid matrix of $\mathrm{DB}_{6} \mathrm{NO}_{2}$ raises the question : is the intermediate phase in the metastable crystalline form a solid antiphase or a true incommensurate phase as above proposed?

Acknowledgments. - It is a real pleasure to aknowledge the kind assistance of Dr. A. M. Levelut for Xray experiments and for valuable discussions. 


\section{References}

[1] Hardouin, F., Levelut, A. M., J. Physique 41 (1980) 41.

[2] Sigaud, G., Nguyen Huu Tinh, Hardouin, F., Gasparoux, H., Mol. Cryst. Liq. Cryst., to be published.

[3] Hardouin, F., Levelut, A. M., Benattar, J. J., Sigaud, S., Solid State Commun. 33 (1980) 337.

[4] Hardouin, F., Levelut, A. M., Sigaud, G., J. Physique 42 (1981) 71

[5] Sigaud, G., Hardouin, F., Achard, M. F., Levelut, A. M., J. Physique 42 (1981) 107.
[6] Prost, J., Proceedings of the liquid crystals of one- and twodimensional order conference, Garmisch-Partenkirchen (1980), Springer series in chemical physics (Springer, Berlin, Heidelberg, New York) 1980.

[7] Prost, J., Proceedings of Colloque Pierre-Curie (1980).

[8] Brownsey, G. J., Leadbetter, A. J., Phys. Rev. Lett. 44 (1980) 1608.

[9] Barois, P., Coulon, C., Prost, J., Colloque Pierre-Curie (1980), to be published. 